\title{
Editorial
}

\section{Prevention of Postoperative Wound Infections: To Cover Up?}

\author{
Christina M.J.E. Vandenbroucke-Grauls, MD, PhD; Jan A. Kluytmans, MD, PhD
}

Gowns, gloves, and masks have been a familiar sight in operating rooms since the beginning of the previous century. Colors and shapes have changed over the years, but the principle of covering body surfaces to prevent the spread of microorganisms from the surgical team to the surgical wound has remained unchanged.

The notion that surgical-wound infection is the result of contamination of the wound with microorganisms during the operation goes back even further, almost 150 years, to Lister, who was the first surgeon to realize the meaning of the studies of Pasteur. He introduced disinfection of hands and instruments with carbolic acid and emphasized that bacteria in the air should be killed with carbolic acid sprayed above the wound. In those days, the surgical team wore normal clothes (Figure). Since Lister's time, disinfectants for the skin of the patient and the hands of the surgeon, the layout of operating rooms to ensure clean air, and the wearing of gowns, masks, and gloves all have improved. With the introduction of antibiotic prophylaxis at the end of the 1960s, the frequency of surgical-site infections (SSIs) has fallen to its present rates. These developments have enabled surgeons to perform extensive surgical procedures relatively safely.

Recent reports from two SSI surveillance systems (from the United Kingdom ${ }^{1}$ and The Netherlands ${ }^{2}$ ) indicate that the overall frequency of postoperative infections is approximately $3 \%$ to $4 \%$, but the incidence varies with the hospital and the type of surgery. Although this complication rate may seem low, SSIs still are very much dreaded, especially in cardiothoracic and or thopedic surgery, because of their very high morbidity and often devastating consequences.

The major pathogen in SSIs is Staphylococcus aureus: it accounted for almost $40 \%$ of the pathogens identified as causing infections in the survey from the English hospitals ${ }^{1}$ and was responsible for $35 \%$ of the microbiologically documented infections in the Dutch study. ${ }^{2}$ In clean surgical procedures, the impact of $S$ aureus is even greater. $S$ aureus has been the leading cause of SSIs since the 1950s, whereas, in the beginning of the previous century, in the pre-sulfonamide era, streptococci were predominant. ${ }^{3}$ The natural and main niche for $S$ aureus is the human nose, but other skin sites also can be colonized. Many patients and hospital staff members carry these microorganisms. The prevalence of carriage in both groups is $30 \%$ to $35 \%{ }^{4}$ As such, $S$ aureus can be an exogenous or an endogenous cause of SSI.

Before the introduction of antimicrobial prophylaxis in surgery, numerous outbreaks of staphylococcal wound infections caused by carriers among the surgical team were reported, and emphasis was placed on surveillance and detection of carriers. ${ }^{3}$ Since the advent of $\beta$-lactamasestable penicillins and cephalosporins, and since antimicrobial prophylaxis has become common practice, reports of staff-related outbreaks of staphylococcal infections have become more rare. At the same time, evidence has accumulated that the majority of $S$ aureus strains recovered from wound infections are endogenous. ${ }^{5-7}$

The role of airborne bacteria in the pathogenesis of SSIs has been disputed since Lister's time. Careful studies of the presence of viable bacteria suspended in the air have been performed in different settings from the mid-1930s on. ${ }^{3}$ The studies by Lidwell and coworkers ${ }^{8}$ on the use of ultraclean air and exhaust suits showed a significant reduction in infection rates and kindled the interest of orthopedic surgeons and operating room architects in the use of various types of laminar flows to control airflow above the sur-

From the Department of Medical Microbiology and Infection Control (Dr. Vandenbroucke-Grauls), "Vrije Universiteit" Medical Center, Amsterdam; and Amphia Hospital (Dr. Kluytmans), Breda, The Netherlands.

Address reprint requests to Prof. Dr. CMJE Vandenbroucke-Grauls, Dept. of Medical Microbiology and Infection Control, University Hospital "Vrije Universiteit," De Boelelaan 1117, 1081 HV Amsterdam, The Netherlands.

O1-ED-055. Vandenbroucke-Grauls CMJE, Kluytmans JA. Prevention of postoperative wound infections: to cover up? Infect Control Hosp Epidemiol 2001;22:335-337. 


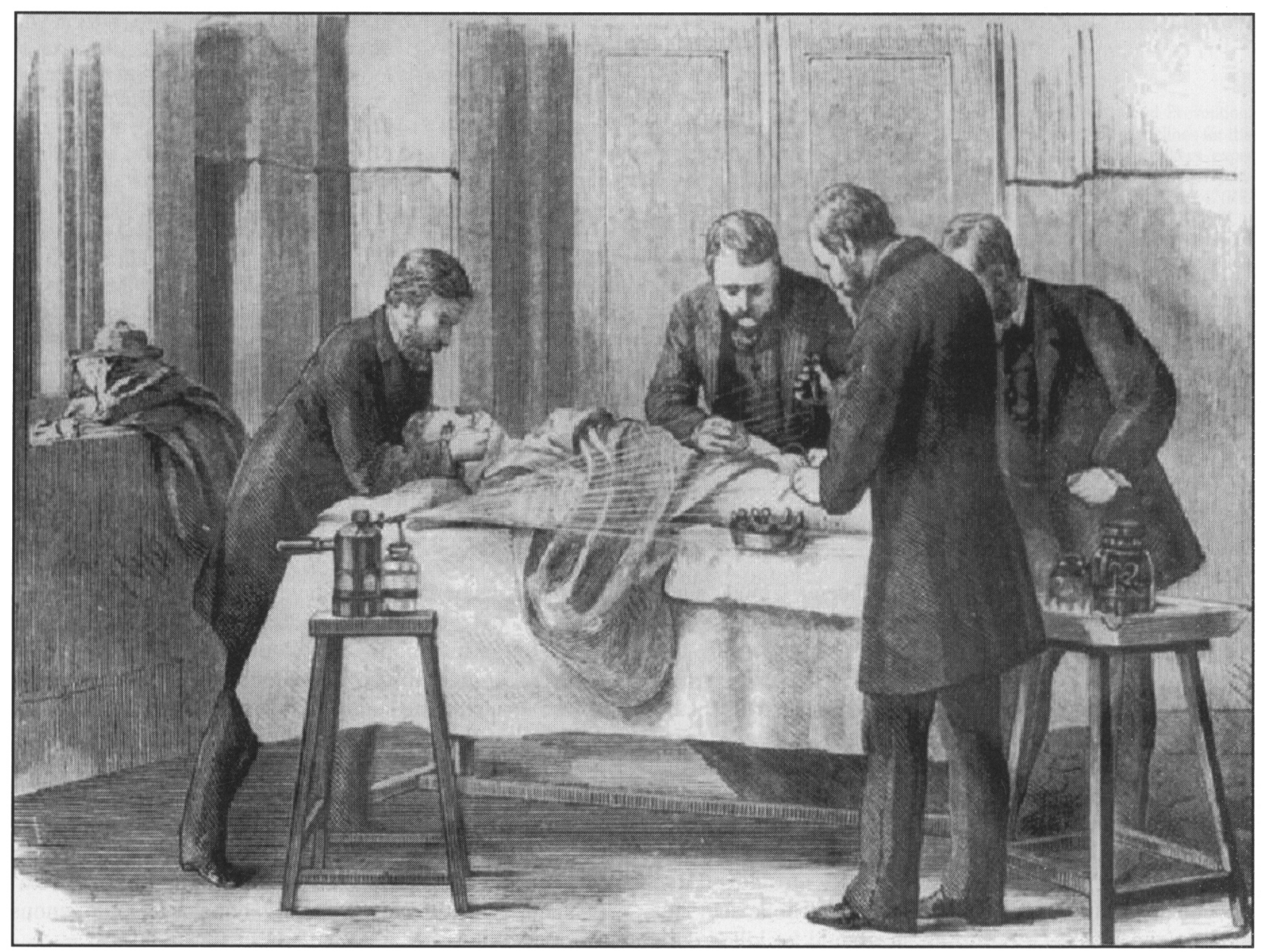

FIGURE. Surgery at the end of the 19 th century.

gical site to prevent airborne bacteria from settling in the wound. The studies on ultraclean air, however, did not take into account the effect of antimicrobial prophylaxis, and so the value of ultraclean air in addition to optimal prophylaxis still is controversial. ${ }^{9}$

Further studies on the pathogenesis of SSIs and on the risk factors that contribute to their development have shown that many factors play a role. ${ }^{10,11}$ These risk factors are at least as important as the cleanliness of the attending surgical team, the air in the operating room, and the timely administration of perioperative antimicrobial agents. The main risk factors are the injury that is imposed on the wound tissues (eg, duration of the operation and skills of the surgeon), the presence of foreign material, and the local and general immunity of the host. No risk factor can be singled out as the most important one; it most probably is the accumulation of risk factors that leads to infection. ${ }^{10}$

The study by Tammelin et al in this issue of the Journal addresses the problem of the surgical staff as dispersers of $S$ aureus. To reduce the numbers of airborne bacteria, a new type of surgical scrub attire, tightly woven and with cuffs at arms and ankles, is compared to scrub suits that are less tightly woven and have no cuffs. From the numbers of bacteria counted in the air during operations, the authors conclude that the new type of scrub suit indeed reduces the dispersal of bacteria from the surgical staff in general and of $S$ aureus in particular. Unfortunately, this does not influence the numbers of staphylococci recovered from the wound surfaces during operation. The number of operations observed is too small to permit a comparison of SSIs; hence, the final impact of this measure on the outcome at stake is not known. As the authors state, a very large number of operations would have to be followed to be able to determine this impact. This is not only because the frequency of infection after clean surgery is low (usually below $5 \%$ ) but probably also because the majority of SSIs caused by $S$ aureus are endogenous. In this respect, it is noteworthy that, before surgery, $S$ aureus was found more often on the patient's skin in the intervention group than in the control group; therefore, it is possible that the two patient groups were not comparable with respect to carriage of $S$ aureus and that this carriage might have influenced the numbers and frequency of recovery of $S$ aureus from the wound walls at the end of the operation. It is well established that $S$ aureus carriage increases the 
risk of wound infection more than sixfold. ${ }^{5}$ Possibly, it affected in a similar way the results of the study by Tammelin et al.

Since Lister, we have learned to appreciate that the operating room should be clean, with a good ventilation rate and strict rules with respect to staff and patient movement. We also know that the development of wound infection is a multifactorial process in which the local and general immunity of the patient is as important as his environment during the operation. Whether additional measures to reduce the numbers of airborne bacteria in the operating room also will reduce the SSI rate remains uncertain.

\section{REFERENCES}

1. NINSS reports on surgical site infection and hospital acquired bacteraemia. Commun Dis Rep CDR Wkly 2000;10:213,216.

2. Geubbels EL, Minties-de Groot AJ, van den Berg JMJ, de Boer AS. An operating surveillance system of surgical-site infections in The Netherlands: results of the PREZIES national surveillance network. Preventie van Ziekenhuisinfecties door Surveillance. Infect Control Hosp Epidemiol 2000;21:311-318.

3. Williams REO, Blowers R, Garrod LP, Shooter RA. Sepsis of surgical wounds. In: Williams REO, Blowers R, Garrod LP, Shooter RA, eds.
Hospital Infection: Causes and Prevention. 2nd ed. London, UK: LloydLuke (Medical Books) Ltd; 1966:77-115.

4. Kluytmans J, van Belkum A, Verbrugh $H$. Nasal carriage of Staphylococcus aureus: epidemiology, underlying mechanisms, and associated risks. Clin Microbiol Rev 1997;10:505-520.

5. Kluytmans JA, Mouton JW, Ijzerman EP, Vandenbroucke-Grauls CM, Maat AW, Wagenvoort JH, et al. Nasal carriage of Staphylococcus aureus as a major risk factor for wound infection after cardiac surgery. $J$ Infect Dis 1995; 171:216-219.

6. Jakob HG, Borneff-Lipp M, Bach A, von Puckler S, Windeler J, Sonntag $\mathrm{H}$, et al. The endogenous pathway is a major route for deep sternal wound infection. Eur J Cardiothorac Surg 2000;17:154-160.

7. Kalmeijer MD, van Nieuwland-Bollen E, Bogaers-Hofman D, de Baere GA. Nasal carriage of Staphylococcus aureus is a major risk factor for surgical-site infections in orthopedic surgery. Infect Control Hosp Epidemiol 2000;21:319-323.

8. Lidwell OM, Lowbury EJ, Whyte W, Blowers R, Stanley SJ, Lowe D. Effect of ultra clean air in operating rooms on deep sepsis in the joint after total hip or total knee replacement : a randomized study. $\mathrm{Br} \mathrm{Med} J$ (Clin Res Ed) 1982;285:10-14.

9. Strachan CJ. The prevention of orthopedic implant and vascular graft infections. J Hosp Infect 1995;30(suppl):54-63.

10. Kluytmans J. Surgical infections including burns. In: Wenzel RP, ed. Prevention and Control of Nosocomial Infections. 3rd ed. Baltimore, MD: Williams \& Wilkins; 1997:841-865.

11. Kernodle DS, Kaiser AB. Postoperative infections and antimicrobial prophylaxis. In: Mandell GL, Bennett JE, Dolin R, eds. Principles and Practice of Infectious Diseases. 5th ed. Philadelphia, PA: Churchill Livingstone; 2000:3177-3191. 